\title{
Skeletal Muscle-derived Hematopoietic Stem Cells: Muscular Dystrophy Therapy by Bone Marrow Transplantation
}

\section{Atsushi Asakura*}

Stem Cell Institute, Paul and Sheila Wellstone Muscular Dystrophy Center, Department of Neurology, University of Minnesota Medical School, Minneapolis, MN, USA

\begin{abstract}
For postnatal growth and regeneration of skeletal muscle, satellite cells, a self-renewing pool of muscle stem cells, give rise to daughter myogenic precursor cells that contribute to the formation of new muscle fibers. In addition to this key myogenic cell class, adult skeletal muscle also contains hematopoietic stem cell and progenitor cell populations which can be purified as a side population (SP) fraction or as a hematopoietic marker CD45-positive cell population. These muscle-derived hematopoietic stem/progenitor cell populations are surprisingly capable of differentiation into hematopoietic cells both after transplantation into irradiated mice and during in vitro colony formation assay. Therefore, these muscle-derived hematopoietic stem/progenitor cells appear to have characteristics similar to classical hematopoietic stem/progenitor cells found in bone marrow. This review outlines recent findings regarding hematopoietic stem/progenitor cell populations residing in adult skeletal muscle and discusses their myogenic potential along with their role in the stem cell niche and related cell therapies for approaching treatment of Duchenne muscular dystrophy.
\end{abstract}

Keywords: Muscle stem cells; Hematopoietic stem cell; Hematopoiesis; Satellite cell; Side population; Skeletal muscle; Muscular dystrophy

\section{Muscle Satellite Cells}

Myogenic satellite cells are a stem cell population that contributes to postnatal muscle growth and regeneration that reside beneath the basal lamina of adult skeletal muscle, closely juxtaposed to the muscle fibers. Satellite cells are normally mitotically quiescent, but following injury or exercise, they initiate proliferation and give rise to daughter myogenic precursor cells [1-3]. After multiple rounds of cell division, these myogenic precursor cells exit their cell cycle and fuse with each other to terminally differentiate into multinucleated myotubes. The selfrenewal capacity within the satellite cell compartment was proven when considering the fact that the number of quiescent satellite cells in adult muscle remains relatively constant over multiple cycles of degeneration and regeneration $[4,5]$. In addition, recent work demonstrates that a small number of satellite cells can robustly contribute to regenerating muscle maintenance of the satellite cell compartment, confirming the proof of concept for stemness of satellite cells [6].

A decade ago, satellite cells were considered monopotent stem cells, with the ability to give rise only to cells of the myogenic cell lineage. Indeed, both quiescent satellite and myogenic precursor cells express markers for myogenic cells such as M-cadherin, Pax3, Pax7, and Myf5 during the quiescent state, and M-cadherin, Pax7, Myf5, MyoD and desmin during myogenic proliferation [7-11]. However, recent experiments have demonstrated that satellite cells possess multipotential differentiation capability. Upon induction, satellite cells are capable of differentiation into adipocytes and osteocytes in vitro $[9,12]$ and fibroblast in vivo [13], indicating a mesenchymal differentiation potential of satellite cells. However, in vivo situation, the ability of adipogenic or osteogenic potential for satellite cells is very limited, and satellite cells may only contribute to skeletal myogenesis in normal situation [14-16]. More recently, satellite cells have been induced to generate induced Pluripotent Stem (iPS) cells by transduction of iPS cell-inducing transcription factors, Oct4, Sox2, cMyc and Klf4 [17-20].

\section{Muscle-derived HSCs}

Current work demonstrates that adult skeletal muscle-derived cells exhibit the capacity to reconstitute the entire hematopoietic repertoire following intravenous injection into lethally irradiated mice [21-29]. Myogenic cells have also been found to form multiple types of hematopoietic colonies by in vitro hematopoietic colony forming assay [25-30]. However, these muscle-derived hematopoietic stem cells (HSCs) and hematopoietic progenitor cells (HPCs) were confirmed as a distinct population from satellite cells [30].

During mouse embryogenesis, the process of primitive hematopoiesis begins in the yolk sac on embryonic day 7.5 (E7.5). Thereafter, definitive HSC activity is first detectable in the aortagonad-mesonephros (AGM) region on E10, and then fetal liver and yolk sac. Subsequently, the fetal liver becomes the main tissue for definitive hematopoiesis by E12. During late embryogenesis, the HSC population in the fetal liver migrates to the bone marrow, which then remains the major site of hematopoiesis throughout adult life [31]. In adult, HSCs and HPCs originating from bone marrow readily colonize the adult spleen. However, it was initially controversial whether HSCs/ HPCs exist outside of bone marrow or spleen. Bartlett [32,33] first reported that a significant amount of hematopoietic colony forming units(spleen, CFU-s), were present in mouse adult brain. The average number of CFU-s obtained per dissociated adult brain-derived cells was significantly higher than those of other adult tissues including lung, kidney, heart, thymus and blood. However, Hoogerbrugge et al. [33]

*Corresponding author: Atsushi Asakura, Stem Cell Institute, University of Minnesota Medical School, McGuire Translational Research Facility, 2001 6th Street. SE, Minneapolis, Minnesota, 55455, USA, Tel: 612-624-7108; Fax: 612624-2436; E-mail: asakura@umn.edu

Received October 22, 2012; Accepted November 15, 2012; Published November 18, 2012

Citation: Asakura A (2012) Skeletal Muscle-derived Hematopoietic Stem Cells: Muscular Dystrophy Therapy by Bone Marrow Transplantation. J Stem Cell Res Ther S11: 005. doi:10.4172/2157-7633.S11-005

Copyright: (c) 2012 Asakura A. This is an open-access article distributed under the terms of the Creative Commons Attribution License, which permits unrestricted use, distribution, and reproduction in any medium, provided the original author and source are credited. 
failed to obtain such high number of CFU-s in adult brain. Therefore, they concluded that the CFU-s detected by Bartlett in preparations of mouse brain did not originate from the brain tissue. Recent work has challenged this question and revealed that HSCs/HPCs clearly exist in several adult tissues besides bone marrow and spleen [30,34]. For example, not only fetal liver but also adult liver has been shown to contain HSCs that reconstitute the entire hematopoiesis lineage in lethally irradiated animals $[35,36]$. In addition, adult lung contains large numbers of alveolar macrophages derived from progenitors [37]. Furthermore, $\mathrm{T}$ cell differentiation occurs in extra-thymic sites, such as intestine and liver [38,39]. For teleosts (fishes), the kidneys are the major hematopoietic organs containing hematopoietic stem cells which are able to be fractionated as side population (SP) cells, and can give rise to all lines of hematopoietic differentiation including erythropoiesis, granulopoiesis, and lymphopoiesis [40,41]. Finally, it was also reported that adult skeletal muscle too contains HSCs and HPCs [21,23].

HSCs in adult skeletal muscle were first discovered by Gussoni et al. [21]. Gussoni et al. [21] purified SP cells positive for HSC marker Sca1 from adult skeletal muscle, intravenously injected these muscle SP cells into lethally irradiated mice, and observed whole hematopoietic contribution in the recipient mice. These resultant data strongly indicated that muscle SP fraction contains HSCs. SP cells exclude Hoechst 33342 DNA-binding dye through the activity at the cell surface of multi-drug resistance (MDR) pomp proteins such as ABCG2/ BCRP1(see in review) [1], which was first reported by Goodell et al. [42]. They also discovered that HSCs in bone marrow from many different species can be isolated as SP cells by fluorescence activated cell sorting (FACS). In vitro hematopoietic colony formation assays confirmed that adult muscle contains a remarkably high level of HPCs that differentiate into multiple types of hematopoietic colonies including myeloid cells, B cells and erythrocytes (see in review) $[1,26,30,34,40,43,44]$. These muscle-derived HPCs can also be enriched in the muscle SP fraction as they are in bone marrow-derived SP cells $[30,34,40,43]$. In addition, only CD45(+) muscle-derived cells display the capacity to give rise to hematopoietic cells in vitro and reconstitute the entire hematopoietic repertoire following intravenous injection into lethally irradiated mice $[1,21,24,45]$, strongly indicating that muscle-derived HSCs and HPCs are indeed of bone-marrow origin. Therefore, circulating HSCs and HPCs originating from bone marrow may reside within skeletal muscle during developmental stages. In this case, marrow-derived cells migrate into skeletal muscle via activity of hepatocyte growth factor (HGF) and its receptor, c-met [46]. Interestingly, Single-cellsorted muscle SP/CD45(+) cells displayed robust proliferative activity [29]. These amplified clonal cell populations displayed multilineage differentiation capability, including myeloid, lymphoid and NK cells. Therefore, similar to bone marrow-derived cells, a single cell in musclederived hematopoietic cells exhibits major proliferative potential and multi-lineage differentiation capability.

With the current understanding of muscle-related hematopoietic status, there are several intriguing questions. 1) How does the muscle niche maintain HSCs/HPCs that possess such a remarkable capability for hematopoietic differentiation potential? 2) Can muscle-derived HSCs/HPCs contribute to muscle regeneration through their direct myogenic differentiation? 3) Can bone marrow-derived HSCs/HPCs contribute to regenerating muscle fibers through their direct myogenic differentiation?

For the muscle niche, a recent paper showed that HPCs occurred in cachectic muscle with a statistically significant enrichment in Sca-
1(+) CD45(+) [47]. Since HSC recruitment is stimulated by muscle injury or other insults [48-50], this phenomenon can be interpreted as a response to signals released by the atrophying fibers to maintain HPCs. Muscle-derived HSCs/HPCs must be abundant in muscle on a whole body basis since muscle is the largest tissue set in the body. Interestingly, Tsuboi et al. demonstrates that frequency of hematopoietic stem cells in human muscle is approximately four times greater than in peripheral blood, suggesting an additional function of human skeletal muscle as a reservoir of HSCs [51]. The presence of HSCs/HPCs in adult muscle raises the possibility that such stem cells locally contribute to host myogenesis when exposed to the correct environment during regeneration. In addition, an interesting question is to what extent non-satellite cells, including muscle-derived HSCs and HPCs, can contribute to regenerating muscle fibers in normal and diseased muscle. Recent work clearly demonstrates that the muscle-derived HSCs/HPCs have been shown to possess myogenic potential, and to contribute to muscle repair by low-level fusion into multinucleated muscle fibers. Regenerative signals in the muscle recruit resident muscle-derived HSCs or HPCs to progress down a myogenic lineage through Wnt signaling and subsequent Pax7 expression $[49,52]$, indicating the participation of muscle-derived HSCs/HPCs in myogenic regeneration.

\section{Myogenic Contribution of HSCs}

Currently, muscle-derived HSCs/HPCs are believed to originate from bone marrow and probably from homing cells of circulating HSCs/HPCs. Several papers have demonstrated the myogenic contribution of bone marrow-derived HSCs/HPCs after intramuscular or intravenous transplantation [21,50,53-64] . Strikingly, single HSC transplantation into lethally irradiated mice demonstrates the clear myogenic contribution of HSCs through intermediate stage myeloid cell differentiation of the engrafted HSCs [56,60-68]. In these cases, the ongoing muscle regeneration and inflammatory cell infiltration are required for HSC-derived contribution. Interestingly, bone marrowderived CD45(+)/Sca-1(+) cells carrying reporter genes controlled by muscle-specific regulatory elements from the Myf5, myosin light chain (MLC3F), or MCK genes, are induced by myoblasts to activate musclespecific genes [69]. However, these cells undergo incomplete myogenic specification and differentiation independently from Pax7 and MyoD. Analysis of muscle chimerism in unirradiated animals joined surgically by parabiosis revealed that contributions of circulating cells to myofibers in the skeletal muscle are injury-dependent and that at least some circulating cells have the potential to contribute to regenerating muscle derived from bone marrow [48]. There are two potential mechanisms for the adoption of a myogenic differentiation fate by the progeny of HSCs. First, myogenic differentiation potential of HSCs could be induced by local muscle environments. Alternatively, the formation of heterokaryons between HSCs and myoblasts and/or regenerating muscle fibers through cell fusion could lead to nuclear reprogramming [60]. Latter case is most likely since circulating HSCderived myeloid progenitor cells, in response to inflammatory cues, migrate to regenerating skeletal muscle and stochastically incorporate into mature myofibers possibly by direct cell fusion process. Potential mechanism for fusion process of myeloid cells may be mediated by the fusogenic ability of macrophages [56]. However, more primitive HSC derivatives, such as myelomonocytic progenitors, but not CD11bCre-positive macrophages, neutrophils and natural killer cells, can incorporate into regenerating muscle fibers [68]. Therefore, in the future, the exact mechanism for this heterokaryon formation should be elucidated. 
The Kuwana et al. [70] reported the discovery of a primitive cell population termed monocyte-derived multipotential cells (MOMCs), which has a fibroblast-like morphology in culture and a unique phenotype positive for CD14, CD45, CD34 and type I collagen, and were found to originate from HSC-derived circulating CD14(+) monocytes. MOMCs contain progenitors with capacity to differentiate into a variety of nonphagocytes, including bone, cartilage, fat, skeletal and cardiac muscle, neuron, and endothelium, indicating the involvement of MOMCs in repair and regeneration of the damaged tissue [70,71]. Currently, several studies have cautioned us about the potential of bone marrow-derived HSCs/HPCs for muscle regeneration [48,7274]. In addition, bone marrow-derived cells isolated from Tie2-GFP mice do not engraft into skeletal muscle microvasculature but promote angiogenesis after acute injury [75]. Furthermore, recent experiments using transgenic mice for developmental and conditional Pax7 gene knockout strongly indicates that satellite cells are a major cell source for the postnatal muscle regeneration [76,77].

\section{Tissue Resident HSCs}

Many adult tissues besides skeletal muscle, such as brain, heart, lung, kidney, and small intestine contain different amounts of HSCs and/or HPCs that can be also enriched in the CD45(+) and SP fraction [30,34]. Therefore, the HSCs and/or HPCs are normal residents in many adult tissues and might contribute to tissue regeneration. It should be elucidated whether other adult tissue-derived HSCs/HPCs also exhibit the potential of hematopoietic reconstitution of irradiated mice. In vitro hematopoietic colony forming assays demonstrate that bone marrow, skeletal muscle, spleen and liver appear to contain more undifferentiated multipotential myeloid progenitors than the other tissues (brain, heart, lung, kidney, and small intestine), which contain more committed myeloid progenitors, such as macrophages and granulocytes $[1,30,34]$. This observation implies that there are unique characteristics about the skeletal muscle niche that allows it to support the survival and maintenance of HSCs/HPCs. Comparison of mRNA levels in skeletal muscle- and fat tissue-derived CD45(+) SP cells revealed that although they expressed many of the same genes including hematopoietic markers (CD45, CD34, CD14, CD68, Thy-1, VCAM-1 and Sca-1) and other genes (Notch, Cdkn1a/p21, Hes1 and Akt1), fat tissue-derived CD45(+) SP cells expressed higher levels of $c$-kit, whereas muscle-derived CD45(+) SP cells possessed a clear enrichment for several endothelial specific transcripts such as (Endoglin, VE-cadhein, Caveolin-1, ABCG2, PECAM and Flk-1) and other genes (Jag1 and Sparc/Osteonectin), indicating that musclederived CD45(+) SP cells are distinct from those isolated from fat tissue. Thus, CD45(+) SP cells do not simply represent a common pool of circulating progenitors, but seems to possess characteristics likely specified by the tissue niche in which they reside [78]. Recent work demonstrates that stem cells are closely associated with vascular niche in the tissues. For example, satellite cells are positioned in a juxtavascular manner while reciprocally interacting with endothelial cells during differentiation to support angio-myogenesis $[79,80]$. In addition, HSCs reside in a perivascular niche (endothelial cells and perivascular stromal cells) in which multiple cell types express factors that promote HSC maintenance [81].

\section{DMD Therapy by Bone Marrow Transplantation}

In considering translational research of angiogenic and myogenic progenitors, biological relevance in treating muscle dystrophies is a sought after bridge to clinical application. Duchenne Muscular Dystrophy (DMD) is the most common muscular dystrophy in which mutations are found in the dystrophin gene that encodes the primary membrane anchor protein essential for skeletal muscle stability [82]. Definitive skeletal muscle treatment for muscular dystrophy will then likely require restoration of the dystrophin protein complex in all affected muscle groups. One promising approach used to restore dystrophin and regenerate muscle fibers is cell therapy. Looking at the summary of the current state of understanding for cell therapies, bone marrow or HSCs/HPCs transplantation is the potential therapeutic approach for treating muscular dystrophy. With the capacity of this therapy many groups have examined transplantation of bone marrowderived cells into muscular dystrophy animal models. As a result, several papers showed some contributions of bone marrow-derived cell transplantation to skeletal muscle fibers in several muscular dystrophy model and spinal muscular atrophy model mice [21,83-92], while other papers reported negative results $[72,93,94]$. Interestingly, the Gussoni et al. [95] reported the analysis of muscle biopsies from a DMD patient who received bone marrow transplantation at age 1 year for severe combined immune deficiency. Analysis of muscle biopsies from this patient at age 12 years revealed the presence of donor nuclei within a small number of muscle myofibers (0.5-0.9\%), indicating the contribution of donor-derived bone marrow cells to DMD host muscle fibers [95]. In addition, bone marrow transplantation in a human patient with Diamond-Blackfan anemia and co-existing DMD demonstrated that in a patient with $100 \%$ donor chimerism of the hematopoietic system, muscle tissue presented $8 \%$ to $10.4 \%$ of cells being of donor origin, indicating promising effects for bone marrow transplantation to muscular dystrophy [96].

The muscle-derived HSCs/HPCs are capable of differentiation into hematopoietic cells in vitro and in vivo, and thus these musclederived HSCs/HPCs appear to have characteristics similar to classical hematopoietic stem/progenitor cells found in bone marrow. Clearly, further experimentation is required to investigate the origin, biological significance and the cellular niche for the HSCs/HPCs within nonhematopoietic tissues. A new and encouraging route in this investigation is the possibility to find wider application for the use of muscle-derived and/or bone marrow-derivedHSCs/HPCs as a potential cell therapy for muscular dystrophy.

\section{Acknowledgement}

We thank Christopher T. Tastad for critical reading of the manuscript. This work was supported by grants from National Institute of Arthritis and Musculoskeleta and Skin Diseases (NIAMS) and the Muscular Dystrophy Association (MDA).

\section{References}

1. Asakura A (2003) Stem cells in adult skeletal muscle. Trends Cardiovasc Med 13: $123-128$.

2. Chargé SB, Rudnicki MA (2004) Cellular and molecular regulation of muscle regeneration. Physiol Rev 84: 209-238.

3. Buckingham M, Montarras D (2008) Skeletal muscle stem cells. Curr Opin Genet Dev 18: 330-336.

4. Gibson MC, Schultz E (1983) Age-related differences in absolute numbers of skeletal muscle satellite cells. Muscle Nerve 6: 574-580.

5. Schultz E, Jaryszak DL (1985) Effects of skeletal muscle regeneration on the proliferation potential of satellite cells. Mech Ageing Dev 30: 63-72.

6. Sacco A, Doyonnas R, Kraft P, Vitorovic S, Blau HM (2008) Self-renewal and expansion of single transplanted muscle stem cells. Nature 456: 502-506.

7. Beauchamp JR, Heslop L, Yu DS, Tajbakhsh S, Kelly RG, et al. (2000) Expression of CD34 and Myf5 defines the majority of quiescent adult skeletal muscle satellite cells. J Cell Biol 151: 1221-1234 
Citation: Asakura A (2012) Skeletal Muscle-derived Hematopoietic Stem Cells: Muscular Dystrophy Therapy by Bone Marrow Transplantation. J Stem Cell Res Ther S11: 005. doi:10.4172/2157-7633.S11-005

8. Seale P, Sabourin LA, Girgis-Gabardo A, Mansouri A, Gruss P, et al. (2000) Pax7 is required for the specification of myogenic satellite cells. Cell 102: 777 786

9. Asakura A, Komaki M, Rudnicki M (2001) Muscle satellite cells are multipotentia stem cells that exhibit myogenic, osteogenic, and adipogenic differentiation. Differentiation 68: 245-253.

10. Montarras D, Morgan J, Collins C, Relaix F, Zaffran S, et al. (2005) Direct isolation of satellite cells for skeletal muscle regeneration. Science 309: 20642067.

11. Hirai H, Verma M, Watanabe S, Tastad C, Asakura Y, et al. (2010) MyoD regulates apoptosis of myoblasts through microRNA-mediated down-regulation of Pax3. J Cell Biol 191: 347-365.

12. Wada MR, Inagawa-Ogashiwa M, Shimizu S, Yasumoto S, Hashimoto N (2002) Generation of different fates from multipotent muscle stem cells. Development 129: 2987-2995.

13. Brack AS, Conboy MJ, Roy S, Lee M, Kuo CJ, et al. (2007) Increased Wnt signaling during aging alters muscle stem cell fate and increases fibrosis. Science 317: 807-810.

14. Uezumi A, Fukada S, Yamamoto N, Takeda S, Tsuchida K (2010) Mesenchymal progenitors distinct from satellite cells contribute to ectopic fat cell formation in skeletal muscle. Nat Cell Biol 12: 143-152.

15. Joe AW, Yi L, Natarajan A, Le Grand F, So L, et al. (2010) Muscle injury activates resident fibro/adipogenic progenitors that facilitate myogenesis. Nat Cell Biol 12: 153-163.

16. Starkey JD, Yamamoto M, Yamamoto S, Goldhamer DJ (2011) Skeletal muscle satellite cells are committed to myogenesis and do not spontaneously adopt nonmyogenic fates. J Histochem Cytochem 59: 33-46.

17. Watanabe S, Hirai H, Asakura Y, Tastad C, Verma M, et al. (2011) MyoD gene suppression by Oct4 is required for reprogramming in myoblasts to produce induced pluripotent stem cells. Stem Cells 29: 505-516.

18. Ahmed RP, Haider HK, Buccini S, Li L, Jiang S, et al. (2011) Reprogramming of skeletal myoblasts for induction of pluripotency for tumor-free cardiomyogenesis in the infarcted heart. Circ Res 109: 60-70.

19. Tan KY, Eminli S, Hettmer S, Hochedlinger K, Wagers AJ (2011) Efficient generation of iPS cells from skeletal muscle stem cells. PLoS One 6: e26406.

20. Trokovic R, Weltner J, Manninen T, Mikkola M, Lundin K, et al. (2012) Smal Molecule Inhibitors Promote Efficient Generation of Induced Pluripotent Stem Cells From Human Skeletal Myoblasts. Stem Cells Dev [Epub ahead of print].

21. Gussoni E, Soneoka Y, Strickland CD, Buzney EA, Khan MK, et al. (1999) Dystrophin expression in the $\mathrm{mdx}$ mouse restored by stem cell transplantation. Nature 401: 390-394.

22. Pang W (2000) Role of muscle-derived cells in hematopoietic reconstitution of irradiated mice. Blood 95: 1106-1108.

23. Jackson KA, Mi T, Goodell MA (1999) Hematopoietic potential of stem cells isolated from murine skeletal muscle. Proc Natl Acad Sci USA 96: 1448214486.

24. Kawada H, Ogawa M (2001) Bone marrow origin of hematopoietic progenitors and stem cells in murine muscle. Blood 98: 2008-2013.

25. Kawada H, Ogawa M (2001) Hematopoietic progenitors and stem cells in murine muscle. Blood Cells Mol Dis 27: 605-609.

26. Geiger H, True JM, Grimes B, Carroll EJ, Fleischman RA, et al. (2002) Analysis of the hematopoietic potential of muscle-derived cells in mice. Blood 100: 721 -

27. Issarachai S, Priestley GV, Nakamoto B, Papayannopoulou T (2002) Cells with hemopoietic potential residing in muscle are itinerant bone marrow-derived cells. Exp Hematol 30: 366-373.

28. Farace F, Prestoz L, Badaoui S, Guillier M, Haond C, et al. (2004) Evaluation of hematopoietic potential generated by transplantation of muscle-derived stem cells in mice. Stem Cells Dev 13: 83-92.

29. Haond C, Drouet M, Derdouch S, Bonnet ML, Norol F, et al. (2008) In vitro and in vivo evaluation of the haematopoietic potential of skeletal muscle in a nonhuman primate model. Bone Marrow Transplant 41: 579-584.

30. McKinney-Freeman SL, Jackson KA, Camargo FD, Ferrari G, Mavilio F, et al. (2002) Muscle-derived hematopoietic stem cells are hematopoietic in origin Proc Natl Acad Sci USA 99: 1341-1346.

31. Yoder MC (2001) Introduction: spatial origin of murine hematopoietic stem cells. Blood 98: 3-5.

32. Bartlett PF (1982) Pluripotential hemopoietic stem cells in adult mouse brain Proc Natl Acad Sci USA 79: 2722-2725.

33. Hoogerbrugge PM, Wagemaker G, van Bekkum DW (1985) Failure to demonstrate pluripotential hemopoietic stem cells in mouse brains. Proc Nat Acad Sci USA 82: 4268-4269.

34. Asakura A, Rudnicki MA (2002) Side population cells from diverse adult tissues are capable of in vitro hematopoietic differentiation. Exp Hematol 30: 13391345.

35. Taniguchi H, Toyoshima T, Fukao K, Nakauchi H (1996) Presence of hematopoietic stem cells in the adult liver. Nat Med 2: 198-203.

36. Kotton DN, Fabian AJ, Mulligan RC (2005) A novel stem-cell population in adult liver with potent hematopoietic-reconstitution activity. Blood 106: 1574-1580.

37. Sorokin SP, McNelly NA, Hoyt RF Jr (1992) CFU-rAM, the origin of lung macrophages, and the macrophage lineage. Am J Physiol 263: L299-L307.

38. Mosley RL, Styre D, Klein JR (1990) Differentiation and functional maturation of bone marrow-derived intestinal epithelial T cells expressing membrane T cel receptor in athymic radiation chimeras. J Immunol 145: 1369-1375.

39. Watanabe H, Miyaji C, Seki S, Abo T (1996) c-kit+ stem cells and thymocyte precursors in the livers of adult mice. J Exp Med 184: 687-693.

40. Traver D, Paw BH, Poss KD, Penberthy WT, Lin S, et al. (2003) Transplantation and in vivo imaging of multilineage engraftment in zebrafish bloodless mutants. Nat Immunol 4: 1238-1246.

41. Kobayashi I, Saito K, Moritomo T, Araki K, Takizawa F, et al. (2008) Characterization and localization of side population (SP) cells in zebrafish kidney hematopoietic tissue. Blood 111: 1131-1137.

42. Goodell MA, Brose K, Paradis G, Conner AS, Mulligan RC (1996) Isolation and functional properties of murine hematopoietic stem cells that are replicating in vivo. J Exp Med183: 1797-1806.

43. Asakura A, Seale P, Girgis-Gabardo A, Rudnicki MA (2002) Myogenic specification of side population cells in skeletal muscle. J. Cell Biol 159: 123 134

44. Asakura A (2007) Hematopoietic potential cells in skeletal muscle. Cell Res 17: 836-638.

45. McKinney-Freeman SL, Majka SM, Jackson KA, Norwood K, Hirschi KK (2003) Altered phenotype and reduced function of muscle-derived hematopoietic stem cells. Exp Hematol 31: 806-814.

46. Rosu-Myles M, Stewart E, Trowbridge J, Ito CY, Zandstra P, et al. (2005) A unique population of bone marrow cells migrates to skeletal muscle via hepatocyte growth factor/c-met axis. J Cell Sci 118: 4343-4352.

47. Berardi E, Aulino P, Murfuni I, Toschi A, Padula F, et al. (2008) Skeletal muscle is enriched in hematopoietic stem cells and not inflammatory cells in cachectic mice. Neurol Res 30: 160-169.

48. Sherwood RI, Christensen JL, Conboy IM, Conboy MJ, Rando TA, et al. (2004) Isolation of adult mouse myogenic progenitors: functional heterogeneity of cells within and engrafting skeletal muscle. Cell 119: 543-554.

49. Polesskaya A, Seale $P$, Rudnicki MA (2003) Wnt signaling induces the myogenic specification of resident CD45+ adult stem cells during muscle regeneration. Cell 113: 841-852.

50. Musarò A, Giacinti C, Borsellino G, Dobrowolny G, Pelosi L, et al. (2004) Stem cell-mediated muscle regeneration is enhanced by local isoform of insulin-like growth factor 1. Proc Natl Acad Sci USA 101: 1206-1210.

51. Tsuboi K, Kawada H, Toh E, Lee YH, Tsuma M, et al. (2005) Potential and 
Citation: Asakura A (2012) Skeletal Muscle-derived Hematopoietic Stem Cells: Muscular Dystrophy Therapy by Bone Marrow Transplantation. J Stem Cell Res Ther S11: 005. doi:10.4172/2157-7633.S11-005

Page 5 of 6

origin of the hematopoietic population in human skeletal muscle. Leuk Res 29: 317-324

52. Seale P, Ishibashi J, Scimè A, Rudnicki MA (2004) Pax7 is necessary and sufficient for the myogenic specification of CD45+:Sca1+ stem cells from injured muscle. PLoS Biol 2: E130.

53. Ferrari G, Cusella-De Angelis G, Coletta M, Paolucci E, Stornaiuolo A, et al. (1998) Muscle regeneration by bone marrow-derived myogenic progenitors. Science 279: 1528-1530.

54. LaBarge MA, Blau HM (2002) Biological progression from adult bone marrow to mononucleate muscle stem cell to multinucleate muscle fiber in response to injury. Cell 111: 589-601.

55. Brazelton TR, Nystrom M, Blau HM (2003) Significant differences among skeletal muscles in the incorporation of bone marrow-derived cells. Dev Biol 262: 64-74.

56. Camargo FD, Green R, Capetanaki Y, Jackson KA, Goodell MA (2003) Single hematopoietic stem cells generate skeletal muscle through myeloid intermediates. Nat Med 9: 1520-1527.

57. Dreyfus PA, Chretien F, Chazaud B, Kirova Y, Caramelle P, et al. (2004) Adult bone marrow-derived stem cells in muscle connective tissue and satellite cell niches. Am J Pathol 164: 773-779.

58. Mori J, Ishihara Y, Matsuo K, Nakajima H, Terada N, et al. (2008) Hematopoietic contribution to skeletal muscle regeneration in acid alpha-glucosidase knockout mice. J Histochem Cytochem 56: 811-817.

59. Luth ES, Jun SJ, Wessen MK, Liadaki K, Gussoni E, et al. (2008) Bone marrow side population cells are enriched for progenitors capable of myogenic differentiation. J Cell Sci 121: 1426-1434.

60. Corbel SY, Lee A, Yi L, Duenas J, Brazelton TR, et al. (2003) Contribution of hematopoietic stem cells to skeletal muscle. Nat Med 9: 1528-1532.

61. Rivier F, Alkan O, Flint AF, Muskiewicz K, Allen PD, et al. (2004) Role of bone marrow cell trafficking in replenishing skeletal muscle SP and MP cell populations. J Cell Sci 117: 1979-1988.

62. Abedi M, Greer DA, Colvin GA, Demers DA, Dooner MS, et al. (2004) Robust conversion of marrow cells to skeletal muscle with formation of marrow-derived muscle cell colonies: a multifactorial process. Exp Hematol 32: 426-434.

63. Ojima K, Uezumi A, Miyoshi H, Masuda S, Morita Y, et al. (2004) Mac-1(low) early myeloid cells in the bone marrow-derived SP fraction migrate into injured skeletal muscle and participate in muscle regeneration. Biochem Biophys Res Commun 321: 1050-1061.

64. Palermo AT, Labarge MA, Doyonnas R, Pomerantz J, Blau HM (2005) Bone marrow contribution to skeletal muscle: a physiological response to stress. Dev Biol 279: 336-344.

65. Yoshimoto M, Chang H, Shiota M, Kobayashi H, Umeda K, et al. (2005) Two different roles of purified CD45+c-Kit+Sca-1+Lin- cells after transplantation in muscles. Stem Cells 23: 610-618.

66. Sacco A, Doyonnas R, LaBarge MA, Hammer MM, Kraft P, et al. (2005) IGF-I increases bone marrow contribution to adult skeletal muscle and enhances the fusion of myelomonocytic precursors. J Cell Biol 171: 483-492.

67. Abedi M, Foster BM, Wood KD, Colvin GA, McLean SD, et al. (2007) Haematopoietic stem cells participate in muscle regeneration. $\mathrm{Br} \mathrm{J}$ Haematol 138: $792-801$.

68. Doyonnas R, LaBarge MA, Sacco A, Charlton C, Blau HM (2004) Hematopoietic contribution to skeletal muscle regeneration by myelomonocytic precursors. Proc Natl Acad Sci USA 101: 13507-13512.

69. Xynos A, Corbella P, Belmonte N, Zini R, Manfredini R, et al. (2010) Bone marrow-derived hematopoietic cells undergo myogenic differentiation following a Pax-7 independent pathway. Stem Cells 28: 965-973.

70. Kuwana M, Okazaki Y, Kodama H, Izumi K, Yasuoka H, et al. (2003) Human circulating CD14+ monocytes as a source of progenitors that exhibit mesenchymal cell differentiation. J Leukoc Biol 74: 833-845.

71. Seta N, Kuwana M (2010) Derivation of multipotent progenitors from human circulating CD14+ monocytes. Exp Hematol 38: 557-563.

72. Lapidos KA, Chen YE, Earley JU, Heydemann A, Huber JM, et al. (2004) Transplanted hematopoietic stem cells demonstrate impaired sarcoglycan expression after engraftment into cardiac and skeletal muscle. J Clin Invest 114: 1577-1585.

73. Wernig G, Janzen V, Schäfer R, Zweyer M, Knauf U, et al. (2005) The vast majority of bone-marrow-derived cells integrated into $\mathrm{mdx}$ muscle fibers are silent despite long-term engraftment. Proc Natl Acad Sci USA 102: 11852 11857.

74. Yablonka-Reuveni Z (2009) Donor-derived hematopoietic cell contribution to myofibers in acid alpha-glucosidase deficiency: a promising progress or back to the beginning?. J Histochem Cytochem 57: 87-88.

75. leronimakis N, Hays A, Reyes M (2012) Bone marrow-derived cells do not engraft into skeletal muscle microvasculature but promote angiogenesis after acute injury. Exp Hematol 40: 238-249.e3.

76. Kuang S, Chargé SB, Seale P, Huh M, Rudnicki MA (2006) Distinct roles for Pax7 and Pax3 in adult regenerative myogenesis. J Cell Biol 172: 103-113.

77. Lepper C, Conway SJ, Fan CM (2009) Adult satellite cells and embryonic muscle progenitors have distinct genetic requirements. Nature 460: 627-631.

78. Andersen DC, Kristiansen GQ, Jensen L, Füchtbauer EM, Schrøder HD, et al (2012) Quantitative gene expression profiling of CD45+ and CD45- skeletal muscle-derived side population cells. Cytometry A 81: 72-80.

79. Christov C, Chrétien F, Abou-Khalil R, Bassez G, Vallet G, et al. (2007) Muscle satellite cells and endothelial cells: close neighbors and privileged partners. Mol Biol Cell 18: 1397-1409.

80. Mounier R, Chrétien F, Chazaud B (2011) Blood vessels and the satellite cel niche. Curr Top Dev Biol 96: 121-138.

81. Ding L, Saunders TL, Enikolopov G, Morrison SJ (2012) Endothelial and perivascular cells maintain haematopoietic stem cells. Nature 481: 457-462.

82. Hartigan-O'Connor D, Chamberlain JS (1999) Progress toward gene therapy of Duchenne muscular dystrophy. Semin Neurol 19: 323-332.

83. Bittner RE, Schöfer C, Weipoltshammer K, Ivanova S, Streubel B, et al. (1999) Recruitment of bone-marrow-derived cells by skeletal and cardiac muscle in adult dystrophic mdx mice. Anat Embryol (Berl) 199: 391-396.

84. Fukada S, Miyagoe-Suzuki Y, Tsukihara H, Yuasa K, Higuchi S, et al. (2002) Muscle regeneration by reconstitution with bone marrow or fetal liver cells from green fluorescent protein-gene transgenic mice. J Cell Sci 115: 1285-1293.

85. Kapsa RM, Quigley AF, Vadolas J, Steeper K, loannou PA (2002) Targeted gene correction in the $\mathrm{mdx}$ mouse using short DNA fragments: towards application with bone marrow-derived cells for autologous remodeling of dystrophic muscle. Gene Ther 9: 695-699.

86. Kapsa RM, Wong SH, Bertoncello I, Quigley AF, Williams B, et al. (2002) CD45 fraction bone marrow cells as potential delivery vehicles for genetically corrected dystrophin loci. Neuromuscul Disord12: S61-S66.

87. Corti S, Strazzer S, Del Bo R, Salani S, Bossolasco P, et al. (2002) A subpopulation of murine bone marrow cells fully differentiates along the myogenic pathway and participates in muscle repair in the $\mathrm{mdx}$ dystrophic mouse. Exp Cell Res 277: 74-85.

88. Chretien F, Dreyfus PA, Christov C, Caramelle P, Lagrange JL, et al. (2005) In vivo fusion of circulating fluorescent cells with dystrophin-deficient myofibers results in extensive sarcoplasmic fluorescence expression but limited dystrophin sarcolemmal expression. Am J Pathol 166: 1741-1748.

89. Hagiwara H, Ohsawa Y, Asakura S, Murakami T, Teshima T, et al. (2006) Bone marrow transplantation improves outcome in a mouse model of congenital muscular dystrophy. FEBS Lett 580: 4463-4468.

90. Salah-Mohellibi N, Millet G, André-Schmutz I, Desforges B, Olaso R, et al. (2006) Bone marrow transplantation attenuates the myopathic phenotype of a muscular mouse model of spinal muscular atrophy. Stem Cells 24: 2723-2732.

91. Yu M, Zhang C, Zhang Y, Feng S, Yao X, et al. (2007) BM stem cell 
Citation: Asakura A (2012) Skeletal Muscle-derived Hematopoietic Stem Cells: Muscular Dystrophy Therapy by Bone Marrow Transplantation. J Stem Cell Res Ther S11: 005. doi:10.4172/2157-7633.S11-005

transplantation rescues pathophysiologic features of aged dystrophic $\mathrm{mdx}$ muscle. Cytotherapy 9: 44-52.

92. Walsh S, Nygren J, Ponten A, Jovinge S (2011) Myogenic reprogramming of bone marrow derived cells in a $\mathrm{W}(4)(1) \mathrm{Dmd}(\mathrm{mdx})$ deficient mouse model. PLoS One 6: e27500.

93. Ferrari G, Stornaiuolo A, Mavilio F (2001) Failure to correct murine muscular dystrophy. Nature 411: 1014-1015.

94. Kuhr CS, Lupu M, Storb R (2007) Hematopoietic cell transplantation directly into dystrophic muscle fails to reconstitute satellite cells and myofibers. Bio Blood Marrow Transplant13: 886-888

95. Gussoni E, Bennett RR, Muskiewicz KR, Meyerrose T, Nolta JA, et al. (2002) Long-term persistence of donor nuclei in a Duchenne muscular dystrophy patient receiving bone marrow transplantation. J Clin Invest 110: 807-814.

96. Nair V, Das S, Sharma A, Sharma S, Kaur J, et al. (2011) Successful bone marrow transplantation in a patient with Diamond-Blackfan anemia with coexisting Duchenne muscular dystrophy: a case report. J Med Case Rep 5: 216.

This article was originally published in a special issue, Muscle Stem Cells

handled by Editor(s). Dr. Stefano Biressi, Stanford University, USA; Dr. Atsushi Asakura, University of Minnesota Medical School, USA 